\title{
CARTOGRAPHY OF MOROCCAN ARGAN TREE USING COMBINED OPTICAL AND SAR IMAGERY INTEGRATED WITH DIGITAL ELEVATION MODEL
}

\author{
El houcine El moussaoui ${ }^{1}$, Aicha Moumni ${ }^{1}$, Abderrahman Lahrouni $^{1}$ \\ ${ }^{1}$ Faculty of Sciences Semlalia, Cadi Ayyad University, Marrakech, Morocco - (elhou.moussaoui@gmail.com, ach.moumni@gmail.com, \\ lahrouni@uca.ac.ma.)
}

KEY WORDS: Argan tree (Argania spinosa (L.) Skeels) mapping, Optical and Synthetic Aperture Radar (SAR) data, image Classification, Morocco.

\begin{abstract}
:
Forest tree species mapping became easier due to the global availability of high spatio-temporal resolution images acquired from multiple sensors. Such data can lead to better forest resources management. Machine-learning pixel based analysis was performed to multi-spectral Sentinel-2 and Synthetic Aperture Radar Sentinel-1 time series integrated with Digital Elevation Model acquired over Argan forest of Essaouira province, Morocco. The argan tree constitutes a fundamental resource for the populations of this arid area of Morocco. This research aims to use the potential of the combination of multi-sensor data to detect, map and identify argan tree from other forest species using three Machine Learning algorithms: Support Vector Machine (SVM), Maximum Likelihood (ML) and Artificial Neural Networks (ANN). The exploited datasets included Sentinel-1 (S1), Sentinel-2 (S2) time series, Shuttle Radar Topographic Missing Digital Elevation Model (DEM) layer and Ground truth data. We tested several sets of scenarios, including single S1 derived features, single S2 time series and combined S1 and S2 derived layers with DEM scene acquisition. The best results (overall accuracy OA and Kappa coefficient K) obtained from time series of optical data (NDVI): $\mathrm{OA}=86.87 \%, \mathrm{~K}=0.84$, from time series of SAR data $(\mathrm{VV}+\mathrm{VH} / \mathrm{VV})$ : $\mathrm{OA}=45.90 \%, \mathrm{~K}$ $=0.36$, from the combination of optical and SAR time series (NDVI+VH+DEM): OA $=93.01 \%, \mathrm{~K}=0.914$, and from the fusion of optical time series and DEM layer (NDVI+DEM): $\mathrm{OA}=93.25 \%, \mathrm{~K}=0.91$. These results indicate that single-sensor (S2) integrated with the DEM layer led us to obtain the highest classification results.
\end{abstract}

\section{INTRODUCTION}

Optical and SAR remote sensing allows the observation, assessment and monitoring of land dynamics at various spatial and temporal resolutions of the earth's surface. Remote sensing offers, on the one hand, the flexibility to monitor agricultural areas, which change from bare soil at the beginning of the season to dense vegetation during the state of maximum growth, and on the other hand, to construct land cover maps, and the identification of crop types, through the use of classification methods on remote sensing data. The use of optical remote sensing for land cover mapping is well established, and can be considered effective (Moumni and al., 2019; Moumni and al., 2021a), yet it displays some shortcomings when applied at the detailed scale of areas where land cover is complex, or over which cloud cover is frequent (Hoang, 2014). On the other hand, SAR remote sensing is not suitable in this context in the first place. But it has been shown sometimes and depending on the region studied, that it can bring improvements in terms of classification quality when combined with optical remote sensing (Moumni and al., 2021b). Forest cover in arid and semi-arid ecosystems has an important role in maintaining global biodiversity, land use dynamics and other socio-economic aspects, it can provide food and fiber, regulate the hydrological cycle, protect watersheds and their vegetation, water flows and several types of ecological services and services to the people living in these regions and the conservation of a balanced environment for the subsistence of various plant and animal species (Mohajane and al.2017). The semi-arid region of south-western Morocco is home to the argan tree (Argania spinosa) forest, also known as the "arganeraie", which was declared a UNESCO MAB (Man and the Biosphere Reserve) biosphere reserve in 1998 (El Wahidi and al.
2014). Argan tree is a slow-growing tree with a shrubby structure that has a lifespan of over 200 years. It can withstand severe drought (high temperatures up to $50^{\circ} \mathrm{C}$ ) and survive with small amounts of annual water (120mm/year) (Charrouf and Guillaume.1999). This multipurpose forest tree (forestry-fruit- forage) is of high importance for Morocco as much on the biological level, phylogenetic and ecological biodiversity as on the economic and social level. It has great medicinal and therapeutic interests, because of the oil extracted from its fruits. Moreover, this one is very required in cosmetics as a revitalizing agent for the skin and the hair. This ecosystem depends on a balance between resources and human exploitation, and also plays an important role in the fight against desertification and erosion (Faouzi and al. 2015). Despite the various roles of this species, currently, the threat of degradation of the argan tree is a major concern for the population and for scientists. Indeed, we are witnessing a decline in tree cover, both in occupied surface and in tree density. This decline is mainly due to overexploitation and clearing, as well as the almost total absence of natural regeneration (M'hirit and al. 1998). In this context, we chose the rural commune of SMIMOU, which is considered a pilot site by foresters, so that the forest cover which is composed of three types of trees: argan, olive and cedars, around Essaouira in southwest Morocco. The Smimou region is considerably large and varied, and the mountain range covers a large part of it. Many studies have been done on determining the spatial distribution of the argan tree based on the classification of remote sensing. We mention among them, the research that is done by KHALID FAOUZI in 2015, aims to develop an argan tree distribution map in the eastern region of Morocco by means of G.P.S (Global Positioning System) combined to G.I.S (Geographic Information System) (Faouzi and al. 2015), The study under the title, 
'Spatiotemporal monitoring of argan woodlands by optical satellite images with average resolution: application to Mseguina forest South-West of Morocco between 1987 and 2015' ( Defaa and al. 2015), focus on the use of satellite images at medium spatial resolution to examine the influence of the parameters of classification by supervised learning in the improvement of land use maps of the argan tree. Another study provides a mapping of the Argan forest distribution area using 10 SPOT 5 images $(10 \mathrm{~m}$ resolution) is presented by (EL Wahidi and al.2017). However none of these studies has combined the high spatio-temporal optical and SAR. Because of this the opportunity has been taken to present this work. The objective of this research in a first step is to characterize the phenological evolution of the argan tree in the SMIMOU area. In addition, the present study aims to control and discriminate argan tree from other tree species (olive and cedar) using high spatiotemporal optical and SAR remote sensing data.

\section{MATERIALS AND METHODS}

\subsection{Study area}

The area under study is located in the Essaouira province, southeastern part of the Marrakech-Safi region in central morocco near to a small town called Smimou ( $31^{\circ} 12^{\prime} 49^{\prime \prime} \mathrm{N}, 9^{\circ} 42^{\prime} 21^{\prime \prime} \mathrm{O}$ ) (Figure $1)$. The pilot site is characterized by dry climate and intense heat during the summer, (temperatures reaching $45^{\circ} \mathrm{C}$ ), and winters are cold and rainy with temperatures falling down to $5^{\circ} \mathrm{C}$. Forests cover about $38 \%$ of the total Commune area, the land-cover is dominated by two main tree species: the argan (Argania spinosa) and Cedar (Tetraclinis articulata) in the upper parts (Genin and Simenel, 2011). The main activity of the inhabitants is agriculture, which is developing at a slow pace due to conditions that are not favorable to agricultural development (lack of rainfall and groundwater). The production system is based on forestry (argan and Cedar), beekeeping, goat, cattle breeding, and cereal farming (barley, wheat and corn) (Mehdioui and Kahouadji, 2007).

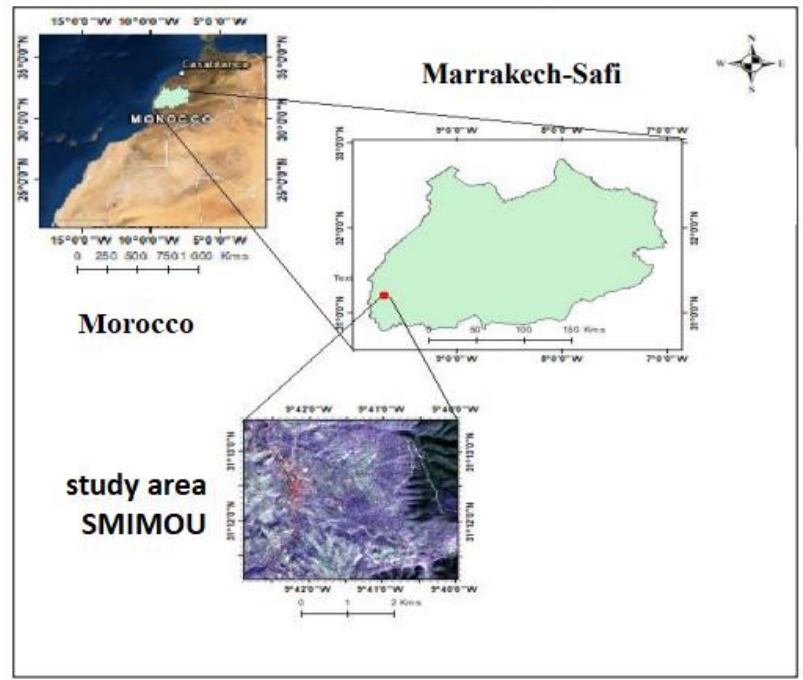

Figure 1. Location of the SMIMOU study site.

The field data are used to extract the profiles and to calibrate or train the classification algorithms, and to validate the results (evaluation of the classification accuracy). Land-cover and land-use samples were gathered via field visits carried out during 2019 in coordination with the local Forestry Research Center (CRF) and were checked additionally by photo interpretation using the very high spatial resolution image on Google Earth's archives and our knowledge of the area The land cover typology was collated into seven main classes that were selected based on their relative abundance in the region.. This typology contains Argan, Cedars, Fallow, Olive, Argan + Cedars, No vegetation and Agriculture.

\subsection{Remote sensing data description}

2.2.1. Optical scene acquisitions: Sentinel-2 images from January 2019 to December 2019 were downloaded from TheiaCNES website (www.theia-land.fr). 36 images (two to three images per month) covering the whole year and well distributed over the 4 seasons were used. The images were projected in WGS 84 UTM, zone $29 N$. Sentinel-2 images were processed to derive products based on a vegetation index called NDVI (Normalized Difference Vegetation Index). This index was introduced by Tucker (1979), is a normalized index to generate an image displaying the vegetation cover (relative biomass) for it represents today the most used vegetation index in remote sensing. NDVI is calculated from the normalized difference of the near-infrared (B-NIR) and red (B-R) bands according to the following equation 1 :

$$
N D V I=\frac{\rho_{N I R}-\rho_{R}}{\rho_{N I R}+\rho_{R}}
$$

Where $\boldsymbol{\rho}_{\boldsymbol{N I R}}$ and $\boldsymbol{\rho}_{\boldsymbol{R}}$ are the reflectance in the near-infrared and red respectively.

2.2.2. SAR scene acquisitions: Sentinel-1 images are orthorectified on the Sentinel-2 grid in order to facilitate the joint use of the two missions. This product named 'S1Tiling' has been developed within the CNES SAR service, in collaboration with CESBIO. The 26 images SAR were collected, covering the year 2019, from Peps website (https://peps.cnes.fr/). Sentinel-1 images need pre-processing before its application. After the download of the images, radiometric and terrain calibration, as well as speckle reduction has been performed. The product has been filtered with Lee Sigma filter 11 x 11 window size. A Range Doppler Terrain Correction with a $30 \mathrm{~m}$ digital elevation model SRTM DEM was used for terrain correction (Kaplan and Avdan, 2018). ESA used the Sentinel-1 toolbox to perform pre-processing in the SNAP software. Following Equation 2, the digital number values were converted to backscattering values in decibel $(\mathrm{dB})$ scale.

$$
\beta^{\circ}{ }_{d b}=10 * \log _{10}\left(\beta^{\circ}\right)
$$

Where $\beta^{\circ}$ is the digital number value of the image, and $\beta^{\circ}{ }_{d b}$ is the backscattered value in $\mathrm{dB}$.

In addition, the texture analysis, gray level co-occurrence matrix (GLCM), was applied to the double polar (VV, VH) Sentinel-1 data (Chen and al, 2020). In this study, eight texture measures are selected which provide the best separability amongst the land cover classes. Those measures are the following: contrast, homogeneity, entropy, mean, variance, angle second moment, dissimilarity and correlation. The texture measures were calculated using a $9 \times 9$ window size with 32 quantization levels in the ENVI software.

2.2.3. DEM layer: The NASA Shuttle Radar Topographic Mission (SRTM) provided digital elevation data (DEMs) for more 
than $80 \%$ of the world. The USGS currently distributes this data for free and can be downloaded from the National Map Seamless Data Distribution System or the USGS website. An imagery Digital Elevation Model (DEM), at 30m spatial resolution, covering our study area was acquired from the USGS Earth Explorer (http://earthexplorer.usgs.gov/).

\subsection{Methodology}

The figure 2 represents the methodological approach followed in the present study.

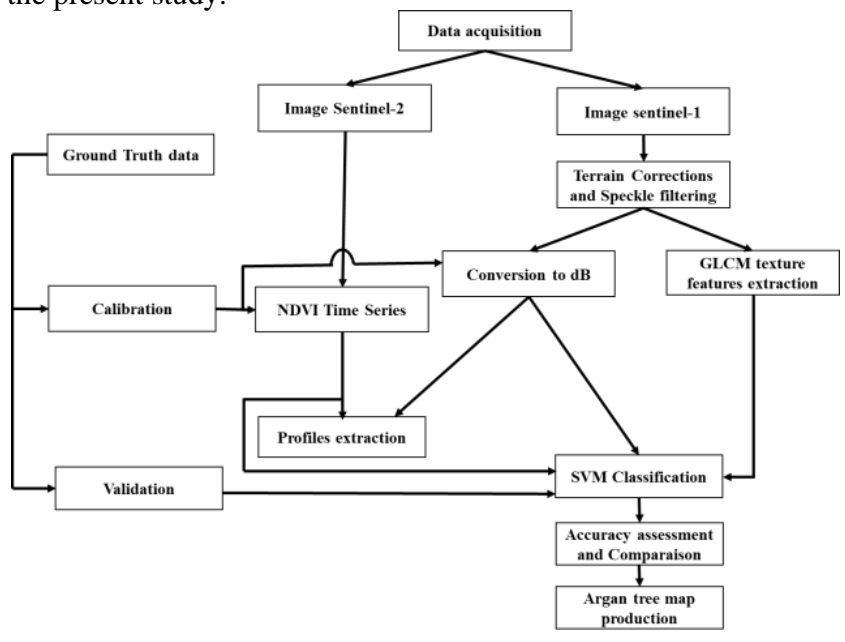

Figure 2. The methodological approach followed in the present work.

2.3.1. Satellite image classification: Among the most frequently used supervised methods in remote sensing are: Maximum Likelihood (Max Lik), that is based on probability methods for each pixel, we identify its probability of belonging to one class rather than another (Perumal, and all, 2010) Neural Network (NN) strongly inspired by the biological nervous system, are composed of simple elements, called neurons. The $\mathrm{NN}$ is used to perform a non-linear classification. This model consists of an input layer, at least one hidden layer and an output layer. It uses the standard inverse propagation for supervised learning. and Support Vector Machine (SVM) It consists in solving a two-class discrimination problem. In a simple way, it is necessary in building, in the space of attributes, a hyperplane separating the image points representing the prototypes of each of the two classes. (Ahmed and all, 2015). In the present study all of these methods were tested to choose the excellent one, the Support Vector Machines (SVM) classifier was chosen as the most successful. In the first step, we started by classifying the time series of single data; optical (NDVI) and SAR (VV, VH, VH/VV, texture features). Then, we combined the data from both sensors and the DEM layer to explore different possible scenarios. Table 1 describes these scenarios in the order followed in image classification.

\begin{tabular}{|c|c|c|}
\hline Scenarios & Bands & Sources \\
\hline 1 & NDVI & Sentinel-2 \\
\hline 2 & VV & Sentinel-1 \\
\hline 3 & VH & Sentinel-1 \\
\hline 4 & $\mathrm{VH} / \mathrm{VV}$ & Sentinel-1 \\
\hline 5 & $\mathrm{VV} ; \mathrm{VH}$ & Sentinel-1 \\
\hline 6 & $\mathrm{VV} ; \mathrm{VH} / \mathrm{VV}$ & Sentinel-1 \\
\hline 7 & $\mathrm{VH} ; \mathrm{VH} / \mathrm{VV}$ & Sentinel-1 \\
\hline 8 & $\begin{array}{c}\text { VV; VH; } \\
\text { VH/VV;Texture }\end{array}$ & Sentinel-1 \\
\hline 9 & $\begin{array}{c}\mathrm{VH} ; \mathrm{VH} / \mathrm{VV} ; \\
\text { Texture } \\
\end{array}$ & Sentinel-1 \\
\hline 10 & NDVI ; VV & $\begin{array}{l}\text { Sentinel-1 } \\
\text { and } 2\end{array}$ \\
\hline 11 & NDVI ; VH & $\begin{array}{l}\text { Sentinel-1 } \\
\text { and } 2\end{array}$ \\
\hline 12 & NDVI ; VH/VV & $\begin{array}{l}\text { Sentinel-1 } \\
\text { and } 2\end{array}$ \\
\hline 13 & $\begin{array}{c}\text { NDVI ; VV ; } \\
\text { VH } \\
\end{array}$ & $\begin{array}{l}\text { Sentinel-1 } \\
\text { and } 2\end{array}$ \\
\hline 14 & $\begin{array}{c}\text { NDVI ; VV ; } \\
\text { VH/VV }\end{array}$ & $\begin{array}{l}\text { Sentinel-1 } \\
\text { and } 2\end{array}$ \\
\hline 15 & $\begin{array}{l}\text { NDVI ; VH ; } \\
\text { VH/VV }\end{array}$ & $\begin{array}{l}\text { Sentinel-1 } \\
\text { and } 2\end{array}$ \\
\hline 16 & NDVI ; VV; VH ; VH/VV & Sentinel-1 and 2 \\
\hline 17 & NDVI; DEM & $\begin{array}{c}\text { Sentinel-2 } \\
\text { And SRTM }\end{array}$ \\
\hline 18 & $\begin{array}{l}\text { NDVI; DEM ;VV } \\
\text { VH/VV ; Texture }\end{array}$ & $\begin{array}{c}\text { Sentinel-1,2 and } \\
\text { SRTM }\end{array}$ \\
\hline
\end{tabular}

Table 1. The scenarios used in the classification process.

2.3.2. Accuracy assessment: The accuracy assessment was evaluated using the generated confusion matrix showing the correspondence between the classification results and ground truth validation data. The diagonal cells represent the number of correctly recognized pixels, the sum of these pixels divided by the total number of pixels indicates the percentage accuracy or overall classification accuracy (OA) (Mama and all, 2003) The Kappa coefficient is another way to quantify the outcome of classification. It was developed by Cohen (1960) and measures the difference between the actual agreement (indicated by the diagonal elements of the matrix) and the Hypothesis Random Agreement (indicated by the product of the row and column margins).

\section{RESULTS AND DISCUSSION}

The NDVI, VV, VH, and VH/VV profiles were computed for each class of the selected ones to study the potential confusions or/and the separability between these different classes and for analyzing and interpreting the classification results. Figure 3 represents, the temporal evolution of the backscattered signals in the C-band (in $\mathrm{VV}, \mathrm{VH}, \mathrm{VH} / \mathrm{VV}$ polarizations). 


\subsection{The profiles}

Figure 3 shows, for each class of the selected ones, the temporal evolution of NDVI and the backscatter coefficient sigma $\sigma$ expressed in decibels of $\mathrm{VV}, \mathrm{VH}$ and $\mathrm{VH} / \mathrm{VV}$ polarizations.
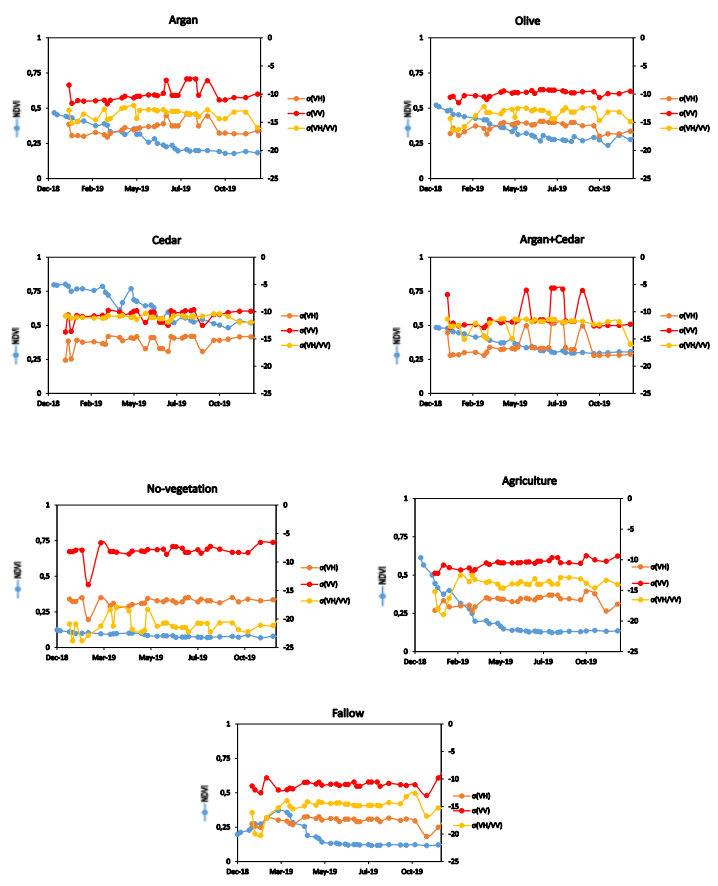

Figure 3. NDVI, $\sigma(\mathrm{VV}), \sigma(\mathrm{VH})$ and $\sigma(\mathrm{VH} / \mathrm{VV})$ profiles of the different classes selected in the study area for 2019.

NDVI profiles: Argan, cedar, cedar + argan and olive can form a group of arboriculture groups, yet we have separated them. The NDVI value of these classes is generally all year higher than 0.2 . Generally, a decreasing trend in the summer is observed, which reflects the low availability of water during the dry season and increasing temperatures during this period. Olive and argan NDVI values range between 0.3 and 0.55 in the winter, and between 0.2 and 0.3 in the summer, the similarity between the signatures of those two classes is quite apparent. Cedars profile presents distinguishably higher values than those of argan and olive (up to 0.8 in winter and higher than 0.5 in summer), thus no separability problem will occur during the classification process. For Agriculture, the beginning of the season (the date when the leaves begin to emerge, which is the start date of the vegetation growth phase) is defined as the time when the rate of increase in NDVI values is higher than the previous successive observations during the vegetation growth period. The end of the season refers to the time during the maturation period when a significant drop in NDVI is observed. Generally it corresponds to the period during which chlorophyll activity progressively decreases (leaves changing from green to yellow color) (Araya and al,2016). Fallow (weeds) resembles annual cereal crops that are cultivated in early December, reaching their maximum development in late March. The no vegetation class is comparatively simple to identify because of the absence of vegetation reflected by NDVI values not exceeding 0.20 throughout the year.

$\sigma(\mathbf{V V}), \sigma(\mathbf{V H})$ and $\sigma(\mathbf{V H} / \mathbf{V V})$ profiles: The two main physical variables that affect the backscattering process are roughness and water content (Moumni and all, 2021). For roughness, it varies from one class to another. However, due to the fact that the region is dry (i.e., semi-arid climate), we can explain the similarity between the backscattered signals of different classes by the low water content of the observed surfaces. This hypothesis is consolidated in several literature works (Torbick and al, 2017; Nguyen and al, 2016; Clauss and al, 2018). In figure 3, it can be seen that for all the selected classes, the intensity values for the $\sigma(\mathrm{VV})$ parallel polarization (values between $-5 \mathrm{~dB}$ and $-11 \mathrm{~dB}$ ) are higher than those for the $\sigma(\mathrm{VH})$ cross-polarization (values between $-13 \mathrm{~dB}$ and $-20 \mathrm{~dB})$, while the values of intensity for $\sigma(\mathrm{VH} / \mathrm{VV})$ are higher than those of the two previous polarizations (varying from $-12 \mathrm{~dB}$ to -17 $\mathrm{dB}$ ), and this for all the selected classes. Furthermore, while the graphs appear to be similar, the signal value ranges are not. We can also see the oscillatory behavior of the argan and cedar classes, as well as their mixture, for which we have no explanation.

\subsection{Classification results}

Table 2 presents the best results of non-combined and combined products in terms of OA and Kappa index. The resulting OA of NDVI time series classification is $86.87 \%(\mathrm{~K}=0.84)$, while the best value of $\mathrm{OA}$ obtained by classifying the time series of SAR products $(\mathrm{VV} ; \mathrm{VH} / \mathrm{VV})$, was $44.43 \%(\mathrm{~K}=0.34)$. While the inclusion of textural features does not bring any improvement on the classification of SAR data. The classification of SAR products over the study area yields significantly lower results than those obtained from optical data (NDVI time series). The combination of Sentinel-1 and Sentinel-2 products does not improve the accuracy of the NDVI scenario, inversely, in this zone, the fusion of the multi-sensor data produces a decrease in the quality of classification results. We note that the addition of the DEM layer to the SAR and optical products increases the accuracy by about $4 \%$ to $5 \%$ whereas the OA of NDVI + DEM was $93.25 \%(\mathrm{~K}=0.91)$.

Table 2. Overall accuracy and Kappa indexes of non combined and combined scenarios

\begin{tabular}{|c|c|c|c|c|c|c|}
\hline & \multicolumn{2}{|c|}{ SVM } & \multicolumn{2}{c|}{ NN } & \multicolumn{2}{c|}{ Max Lik } \\
\cline { 2 - 7 } & OA (\%) & K & OA(\%) & K & OA(\%) & K \\
\hline NDVI & 86.87 & 0.84 & 75.25 & 0.73 & 77.92 & 0.73 \\
\hline VV ; VH/VV & 44.43 & 0.34 & 35.78 & 0.28 & 29.81 & 0.27 \\
\hline VH ; VV ;VH /VV & 43.34 & 0.33 & 33.85 & 0.31 & 27.95 & 0.25 \\
\hline Texture ; VH ; VH/VV & 35.51 & 0.24 & \multicolumn{2}{|c|}{ Overestimation } & 24.79 & 0.20 \\
\hline NDVI ;VV & 85.94 & 0.82 & \multicolumn{2}{|c|}{ Overestimation } & 73.00 & 0.67 \\
\hline NDVI ;VV ;DEM & 90.72 & 0.88 & \multicolumn{2}{|c|}{ Overestimation } & 74.20 & 0.68 \\
\hline NDVI;VH ;VV ; DEM & 88.84 & 0.86 & 62.16 & 0.59 & 64.68 & 0.56 \\
\hline NDVI;VH ;DEM & 90.25 & 0.88 & 69.76 & 0.65 & 72.91 & 0.67 \\
\hline NDVI ;DEM & 93.25 & 0.91 & 70.24 & 0.68 & 82.34 & 0.78 \\
\hline
\end{tabular}


On the other hand, we compared the quality of the classified products (figure 4). We observe distinctions between the Sentinel1 and Sentinel-2 product classifications. In fact, even after the speckle effect has been reduced, the sharpness of the radar classified images is inferior to that of the optical classified images. This is due to widespread confusion of the Argan class with the olive tree, which appears to be dominant on SAR derived maps. For improving the quality of these classified images a smoothing process has been applied.
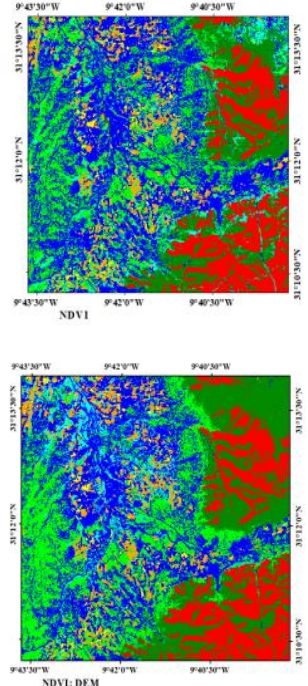
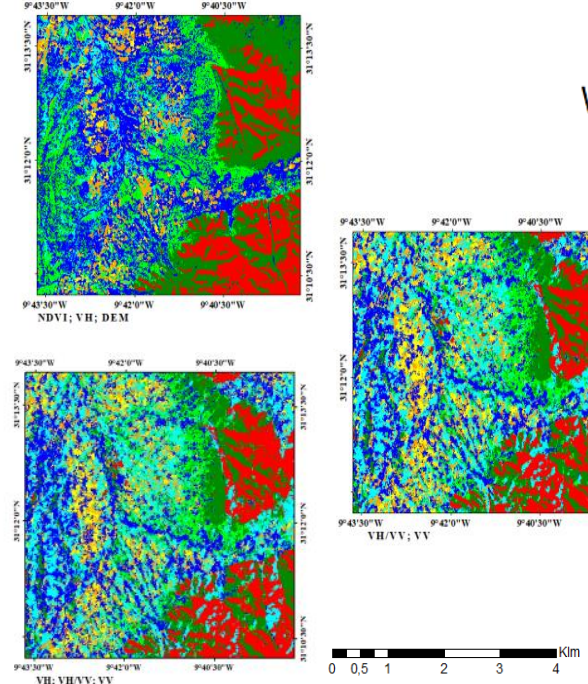<smiles>FC1NC2NC1S2</smiles>
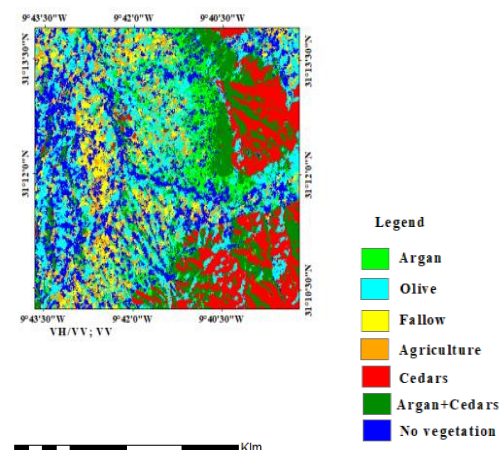

Figure 4. Resulting maps of the best classifications

Smoothing filter: We notice a lack of sharpness in classified images containing SAR data, the images always seem "noisy". Therefore, we applied a smoothing filter on these images through the ENVI command called Majority/Minority Analysis (Yuan and $a l, 2012)$.This latter filters the image by the replacement of the central pixel value of a window of size $\mathrm{n} \times \mathrm{n}$ by the majority value located in this window. We have selected a window with a size of
$3 \times 3$ for avoiding the over-smoothing. The smoothing filter was applied to scenarios including Sentinel-1 images (figure 5). Table 3 shows the OA and Kappa of these scenarios before and after the application of smoothing. The best resulting argan tree maps using the combination of DEM and optical data as well as the combination of DEM, SAR and optical data are shown in figure 6.
Bifore smoothing
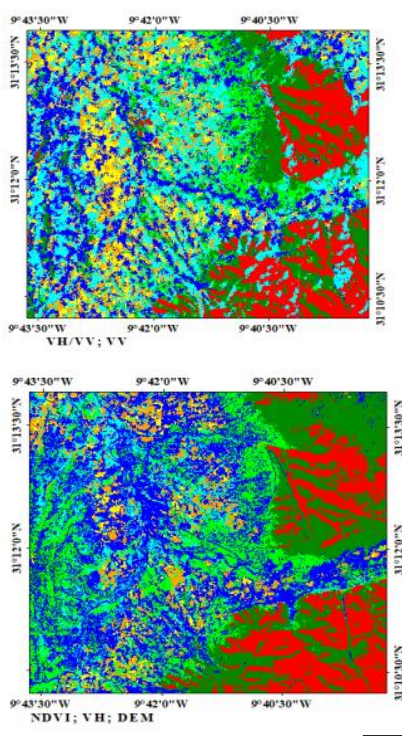

After smoothing

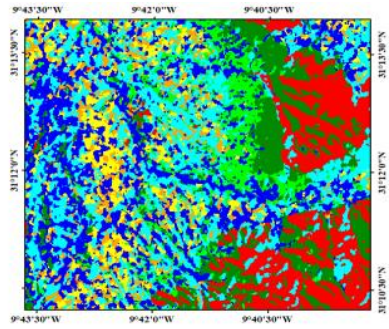<smiles>FC1N=C2SC(N1)C2F</smiles>

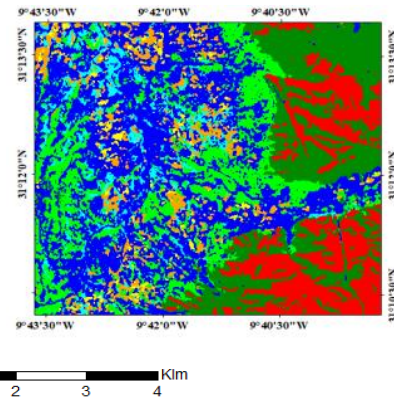

L.

Argan

Fallow

Agricula
cedars

Argan+Cedar

Figure 5. Smoothing of scenario classification (NDVI; VH; DEM). 
The International Archives of the Photogrammetry, Remote Sensing and Spatial Information Sciences, Volume XLVI-4/W5-2021

The 6th International Conference on Smart City Applications, 27-29 October 2021, Karabuk University, Virtual Safranbolu, Turkey

\begin{tabular}{|c|c|c|c|c|c|c|c|c|c|c|c|c|}
\hline \multirow[t]{3}{*}{ Algorithms } & \multicolumn{4}{|c|}{ SVM } & \multicolumn{4}{|c|}{ NN } & \multicolumn{4}{|c|}{ MaxLIK } \\
\hline & \multicolumn{2}{|c|}{$\begin{array}{c}\text { Before } \\
\text { Smoothing }\end{array}$} & \multicolumn{2}{|c|}{$\begin{array}{c}\text { After } \\
\text { Smoothing }\end{array}$} & \multicolumn{2}{|c|}{$\begin{array}{c}\text { Before } \\
\text { Smoothing }\end{array}$} & \multicolumn{2}{|c|}{$\begin{array}{c}\text { After } \\
\text { Smoothing }\end{array}$} & \multicolumn{2}{|c|}{$\begin{array}{c}\text { Before } \\
\text { Smoothing }\end{array}$} & \multicolumn{2}{|c|}{$\begin{array}{c}\text { After } \\
\text { Smoothing }\end{array}$} \\
\hline & $\mathrm{OA}(\%)$ & K & $\mathrm{OA}(\%)$ & K & $\mathrm{OA}(\%)$ & $\mathrm{K}$ & $\mathrm{OA}(\%)$ & $\mathrm{K}$ & $\mathrm{OA}(\%)$ & K & $\mathrm{OA}(\%)$ & $\mathrm{K}$ \\
\hline NDVI ; VV & 85.94 & 0.82 & 88.32 & 0.85 & \multicolumn{4}{|c|}{ Overestimation } & 73.00 & 0.67 & 76.01 & 0.71 \\
\hline $\begin{array}{c}\text { NDVI ; VH ; } \\
\text { VV ;DEM }\end{array}$ & 88.84 & 0.863 & 91.66 & 0.897 & 62.16 & 0.59 & 64.03 & 0.61 & 64.68 & 0.56 & 65.19 & 0.57 \\
\hline VV ; VH/VV & 44.43 & 0.34 & 45.90 & 0.36 & 35.78 & 0.28 & 36.41 & 0.29 & 29.81 & 0.27 & 31.43 & 0.26 \\
\hline $\begin{array}{c}\text { NDVI ; VH ; } \\
\text { DEM }\end{array}$ & 90.25 & 0.88 & 93.01 & 0.914 & 69.76 & 0.65 & 70.21 & 0.67 & 72.91 & 0.67 & 75.93 & 0.70 \\
\hline
\end{tabular}

Table 3. Improvement of the global accuracies and Kappa indices by applying of smoothing.
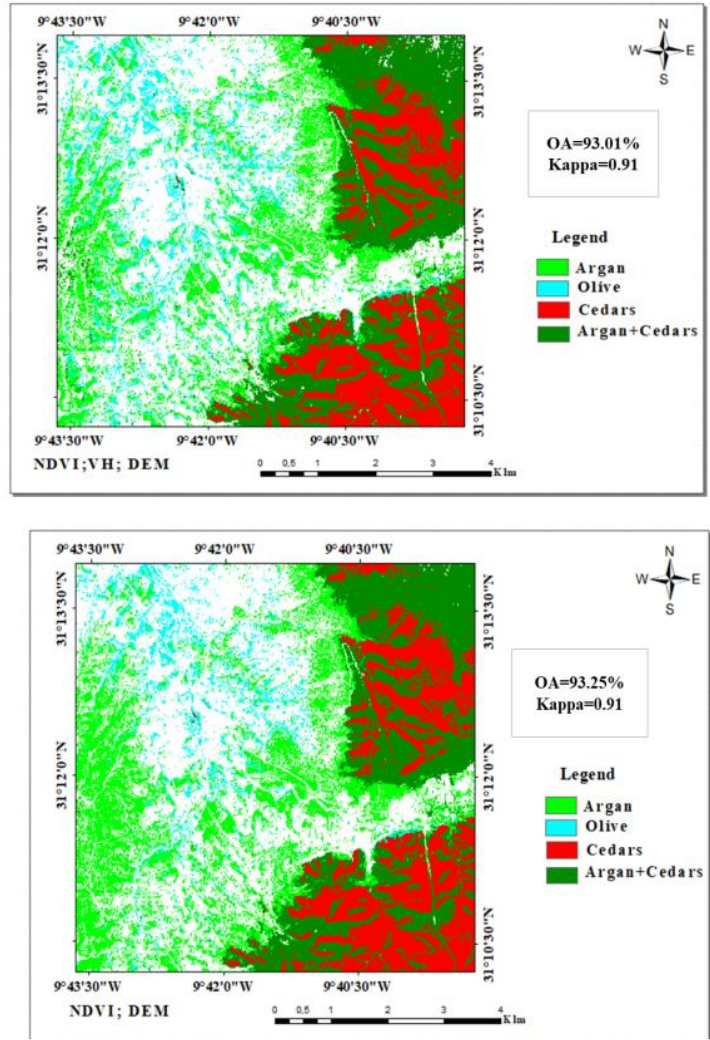

Figure 6. Maps of spatial distribution of the Argan tree using (NDVI; VH; DEM) and (NDVI; DEM).

\section{CONCLUSION}

This study aimed to map the spatial distribution of the argan tree on the rural commune SMIMOU by remote sensing and the evaluation of the contribution of the combination of optical satellite images, SAR and the DEM layer in improving the identification of the forest tree cover and particularly the argan tree. To do this, we began with the acquisition of data. 36 Sentinel-2 images and 26 Sentinel-1 images were downloaded from THEIA and PEPS respectively. In addition, the ground truth information was collected from a field campaign conducted in 2019, and complemented by Google Earth data. The methodology consists in the application of SVM algorithms for the classifications of the Sentinel-2 images, the Sentinel-1 images and the fusion of both sensors' data. The quality of classification results were interpreted visually and showed that the classifications of multi-sensor images containing Sentinel-1 data, still remain noisy despite the fact that the Enhanced Lee filter has been applied to these images before being classified. They contain great spatial extents of olive tree confused with argan tree. In order to improve the accuracy further, we used the technique of smoothing of the post-classified products. Indeed, the results showed an improvement and the classification of Sentinel-1 derived data reached an OA of $45.90 \%(\mathrm{~K}=0.36)$ for the best scenario (VV, VH/ VV). The joint use of the two Sentinel constellation products (Sentinel-1 and Sentinel- 2), contrary to what was expected, led to a decrease in the accuracy and quality of the map, the addition of the DEM layer to the SAR and optical products increases the accuracy by about $4 \%$ to $5 \%$ whereas the OA of NDVI; DEM is $93.25 \%(\mathrm{~K}=0.91)$. In the future, we intend to improve the results of Sentinel-1 images by testing other SAR parameters. This could improve the accuracy of optical and SAR time series combinations. The method will then be generalized to a larger area of Essaouira.

\section{ACKNOWLEDGEMENTS}

The authors would like to thank the Center of Forestry Research CRF (Centre de Recherches Forestières) for their technical support and accompaniment during field campaigns.

\section{REFERENCES}

Ahmed, E. L. M., \& Hassan, C. (2015). Développement des algorithmes pour l'automatisation de la classification des données utilisant les réseaux de neurones probabilistes (PNN). Application à l'analyse, la catégorisation et la cartographie des images de To cite this version : HAL Id.

Clauss, K., Ottinger, M., \&Künzer, C. (2018).Mapping rice areas with Sentinel-1 time series and superpixel segmentation. International journal of remotesensing, 39(5), 1399-1420.

Chen, S., Useya, J., \& Mugiyo, H. (2020). Decision-level fusion of Sentinel-1 SAR and Landsat 8 OLI texture features for crop discrimination and classification: case of Masvingo, Zimbabwe. Heliyon, 6(11), e05358. 
El Wahidi, F., Bellefontaine, R., Quentin, P., \& Defourny, P. (2014). Dynamique de changement de l'arganeraie entre sur- usage et mutations sociales: une opportunité d'équilibre socioécologique?. Journal of Agriculture and Environment for International Development (JAEID), 108(2), 109-133.

Faouzi, K., Rharrabti, Y., Boukroute, A., Mahyou, H., \& Berrichi, A. (2015). Cartographie de l'aire de répartition de l'arganier (Argania spinosa L. Skeels) dans la région orientale du Maroc par le GPS combiné au SIG. Nature \& Technology, 12, 16-24.

Hoang, K. H. (2014).Cartographie de l'occupation du sol du bassin versant de la rivière Câu (Vietnam) au moyen d'images optiques et SAR en support à la modélisation hydrologique (Doctoral dissertation, Université du Québec, Institut national de la recherche scientifique).

Genin, D., \& Simenel, R. (2011). Endogenous Berber forest management and the functional shaping of rural forests in southern Morocco: implications for shared forest management options. Human Ecology, 39(3), 257-269.

Kaplan, G., \& Avdan, U. (2018). SENTINEL-1 AND SENTINEL2 DATA FUSION FOR WETLANDS MAPPING

BALIKDAMI, TURKEY. International Archives of the Photogrammetry, Remote Sensing \& Spatial Information Sciences, 42(3).

Mehdioui, R., \&Kahouadji, A. (2007). Etude ethnobotanique auprès de la population riveraine de la forêt d'Amsittène: cas de la Commune d'Imi n'Tlit (Province d'Essaouira). Bulletin de 1'Institut scientifique, Rabat, section Sciences de la vie, 29, 11- 20. Mama, V. J., \& Oloukoi, J. O. S. E. P. H. (2003). Évaluation de la précision des traitements analogiques des images satellitaires dans l'étude de la dynamique de l'occupation du sol. Télédétection, 3(5), 429-441.

Matsushita, B., Yang, W., Chen, J., Onda, Y., \&Qiu, G. (2007).Sensitivity of the Enhanced Vegetation Index (EVI) and Normalized Difference Vegetation Index (NDVI) to topographic effects: A case study in high-density cypress forest. Sensors, 7(11), 2636- 2651. https://doi.org/10.3390/s7112636

Mehdioui, R., \& Kahouadji, A. (2007). Etude ethnobotanique auprès de la population riveraine de la forêt d'Amsittène: cas de la Commune d'Imi n'Tlit (Province d'Essaouira). Bulletin de l'Institut scientifique, Rabat, section Sciences de la vie, 29, 11- 20. Mohajane, M., Essahlaoui, A., Oudija, F., El Hafyani, M., \& Cláudia Teodoro, A. (2017). Mapping forest species in the central middle atlas of Morocco (Azrou Forest) through remote sensing techniques. ISPRS International Journal of Geo- Information, 6(9), 275.

Moumni, A., Sebbar, B., Simonneaux, V., Ezzahar, J., \& Lahrouni, A. (2019, October). Sample period dependent classification approach for the cartography of crops in the Haouz plain, Morocco. In Remote Sensing for Agriculture, Ecosystems, and Hydrology XXI (Vol. 11149, p. 1114909). International Society for Optics and Photonics.
Moumni, A., Oujaoura, M., Ezzahar, J., \& Lahrouni, A. (2021a). A new synergistic approach for crop discrimination in a semi- arid region using Sentinel-2 time series and the multiple combination of machine learning classifiers. In Journal of Physics: Conference Series (Vol. 1743, No. 1, p. 012026). IOP Publishing.

Moumni, A., \& Lahrouni, A. (2021b). Machine Learning-Based Classification for Crop-Type Mapping Using the Fusion of HighResolution Satellite Imagery in a Semiarid Area. Scientifica, 2021.

Moumni, A., Belghazi, T., Maksoudi, B., \& Lahrouni, A. (2021). Argan Tree (Argania spinosa (L.) Skeels) Mapping Based on Multisensor Fusion of Satellite Imagery in Essaouira Province, Morocco. Journal of Sensors, 2021.

M'hirit, O., Benzyane, M., \&Benchekroune, F. (1998). L'Arganier : Une espèce fruitière-forestière a usages multiples. Mardaga.

Nguyen, D. B., Gruber, A., \& Wagner, W. (2016). Mapping rice extent and cropping scheme in the Mekong Delta using Sentinel1A data. RemoteSensingLetters, 7(12), 1209-1218

Nill, D., \&Böhnert, E. (2006).Value chains for the conservation of biological diversity for food and agriculture.Potatoes in the Andes, Ethiopian coffee, Argan oil from Morocco and grasscuttersinWestAfrica.DeutscheGesellschaftfürTechnischeZ usammenarbeit, Eschborn.Germany and the Global Facilitation Unit for Underutilized Species, Rome.

Perumal, K., \& Bhaskaran, R. (2010). Supervised classification performance of multispectral images. arXiv preprint arXiv:1002.4046.

Torbick, N., Chowdhury, D., Salas, W., \& Qi, J. (2017).Monitoring rice agriculture across myanmar using time series Sentinel-1 assisted by Landsat-8 and PALSAR-2. RemoteSensing, 9(2), 119. Yuan, Q., Cong, G., \& Thalmann, N. M. (2012, April). Enhancing naive bayes with various smoothing methods for short text classification. In Proceedings of the 21st International Conference on World Wide Web (pp. 645-646) 